\title{
Parasitic gastropod bioerosion trace fossil on Cenomanian oysters from Le Mans, France and its ichnologic and taphonomic context
}

Gérard Breton, Max Wisshak, Didier Néraudeau, and Nicolas Morel

Acta Palaeontologica Polonica 62 (1), 2017: 45-57 doi:https://doi.org/10.4202/app.00304.2016

We describe and name Loxolenichnus stellatocinctus Breton and Wisshak igen. et isp. nov., a bioerosion trace fossil on an Upper Cenomanian oyster from Le Mans (France). This trace is attributed here to a parasitic gastropod. The characteristics of this ichnospecies are a combination of one or several, vertical or oblique, complete penetrations, and an asymmetrical attachment etching (fixichnion) with a diagnostic set of stellate grooves increasingly distinct towards the margin of the trace. By including two former Oichnus ichnospecies, Loxolenichnus halo comb. nov. and Loxolenichnus taddei comb. nov., Oichnus, is now constrained to pure predation traces (praedichnia). The numerous oysters collected from the Marnes à Pycnodonte biauriculata Formation show associated epibionts and encrusters as well as borers and scrapers.

Encrusters comprise 24 taxa while bioerosion trace fossils comprise 17 ichnotaxa ranging from very rare (Gnathichnus and Entobia ichnofacies are represented on the shellgrounds, presumably alternatingly.

Key words: Gastropoda, Ostreidae, trace fossil, taphonomy, bioerosion, Cenomanian, Paris Basin.

Gérard Breton [gerard-breton@orange.fr], Géosciences, Université de Rennes I, Campus de Beaulieu, F-35042 Rennes Cedex, France; correspondence address: 6 rue des Réservoirs, 76600 Le Havre, France. Max Wisshak [Max.Wisshak@senckenberg.de], Marine Research Department, Senckenberg am Meer, 26382 Wilhelms-haven, Germany. Didier Néraudeau [didier.neraudeau@univ-rennes1.fr], Géosciences, Université de Rennes I, Campus de Beaulieu, F-35042 Rennes Cedex, France. Nicolas Morel [musee.vert@ ville-lemans.fr], Muséum d'histoire naturelle "Musée Vert", 204 avenue Jean-Jaurès, F-72100 Le Mans, France. 
This is an open-access article distributed under the terms of the Creative Commons

Attribution License (for details please see creativecommons.org), which permits unrestricted use, distribution, and reproduction in any medium, provided the original author and source are credited.

Forif Full text $(1,571.5 \mathrm{kB})$ 